\title{
Unsymmetrical Growth Synthesis of Nontraditional Dendrimers
}

\author{
Lijiao Niu, Xueyan Zhang, and Shengtao Ding*
}

State Key Laboratory of Organic-Inorganic Composites, College of Chemical Engineering, Beijing University of Chemical Technology, Beijing 100029, China.
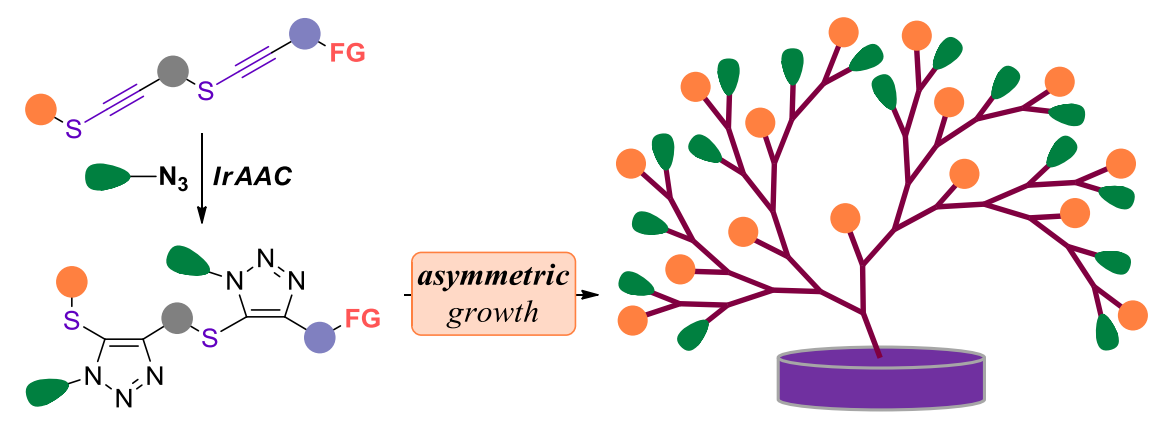

\begin{abstract}
Developing highly complex molecules is of great significance in science and technology. Here we present an unprecedented type of dendrimer assembled from linear ABB-type monomer. The construction of this nontraditional ramified architecture was facilely achieved through one simple convergent strategy established on the iridium-catalyzed cycloaddition of organic azides with internal 1-thioalkynes (IrAAC). By virtue of the unsymmetrically growing fashion in this process, diverse functional groups could be conveniently distributed on both of its exterior and interior layers. Syntheses of two dendrons from the cooperation of one linear alkyne motif with different azides were presented to demonstrate the efficiency and fidelity of this protocol. Postmodifications on their core or periphery were further conducted, resulting in diverse newly functionalized dendrimers with up to $\sim 16.0 \mathrm{kDa}$ molecular weight. The identity and purity of these unsymmetrical dendritic macromolecules were well confirmed by ${ }^{1} \mathrm{H}$ NMR, MS and SEC analysis.
\end{abstract}




\section{INTRODUCTION}

Dendrimers are nanosized tridimensional macromolecules with a well-defined ramified architecture. Their unique chemical and physical properties enable them extraordinary materials for various functional applications, such as drug delivery, protein mimicry, catalysis, light harvesting, coatings, etc. ${ }^{1-8}$ During the past four decades, a tremendous amount of dendrimers with different structures and functions have been created through divergent or convergent synthetic strategies. ${ }^{9,10}$ By virtue of the preparation of dendrons from branched units, they often grow in a symmetrical manner (Scheme 1A). This endows dendrimers involving two or more of dendrons with roughly spherical shapes and three distinct components: central core, internal branches, and terminal groups. Chiefly limited by the nature of their synthesis, functionalities are traditionally placed at the periphery or the core. Incorporation of functional groups at the interior branches is one intriguing way to fully exploit the potential of dendrimers. Nevertheless, reports on internally functionalized dendrimers are still exiguous, which might be mainly due to the difficult preparation of building blocks as well as tedious approaches to the targets. ${ }^{11-24}$ In this context, we envisage the fabrication of nontraditional dendrons from linear ABB-type monomers in an unsymmetrically growing fashion, which will enable the facile distribution of multifunctionality at both of the exterior and interior layers (Scheme 1B). Additionally, with proper design of initial building blocks, dendrimers assembled from these dendrons probably exhibit diverse three-dimensional forms beyond sphericity.

Robust organic reactions are of utmost value for the large-scale production of sophisticated dendritic architectures with high fidelity. Since the first application of copper-catalyzed alkyneazide cycloaddition (CuAAC) in this field, ${ }^{25}$ numerous triazole-involved dendrimers have been created on account of the distinguished advantages of this "click" reaction, including facile and 
Scheme 1. (A) Traditional dendrons from branched units; (B) Nontraditional dendrons from linear units; (C) IrAAC-based design of linear units.
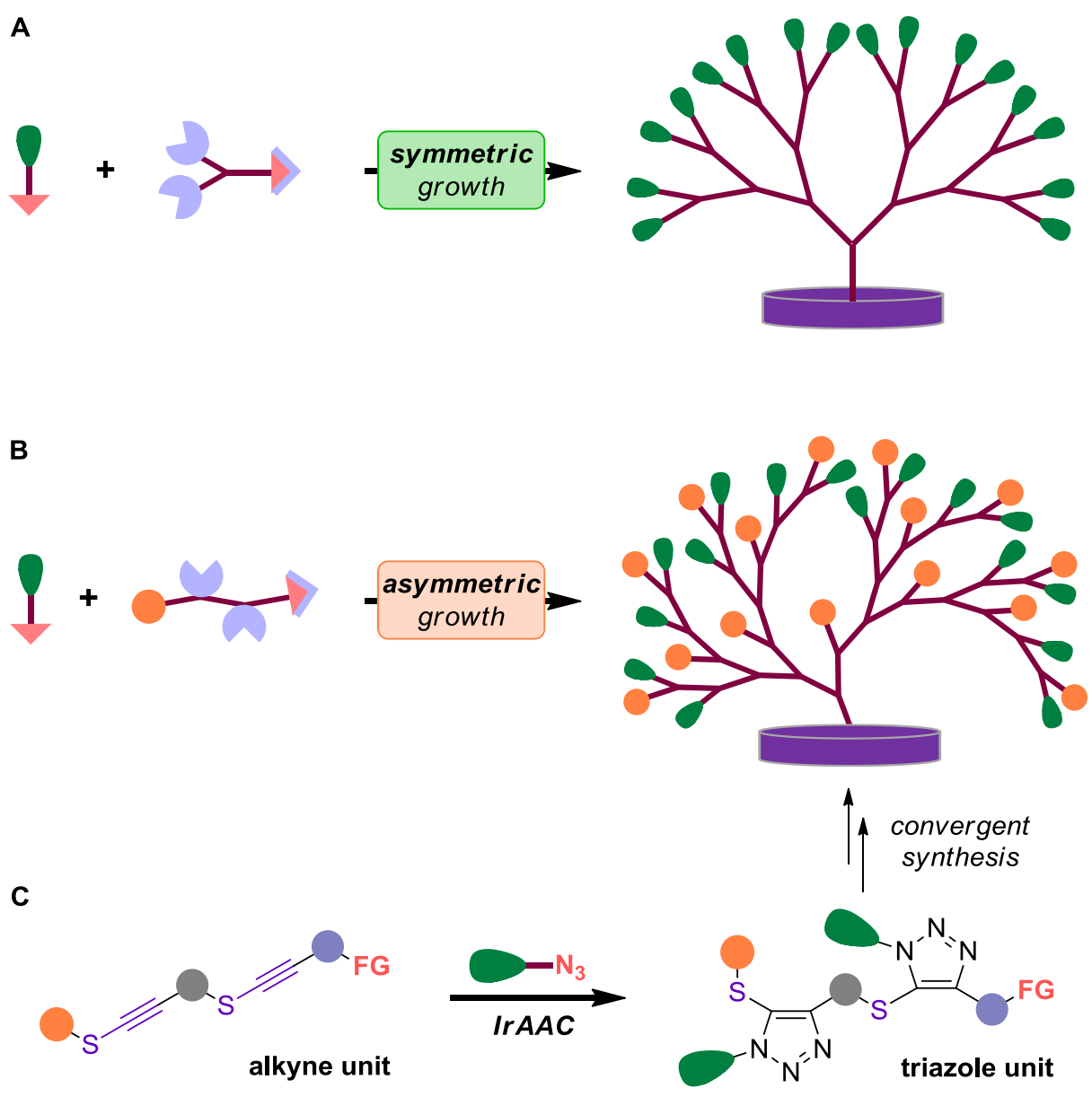

mild conditions, high yields and selectivity, orthogonality, etc. ${ }^{26-31}$ However, only terminal alkynes are tolerated in these cases, thereby limiting the use of triazole rings as linkages. In recent years, the annulation of internal alkynes with azides has been realized under different catalytic systems. ${ }^{32}$ One emblematic example is the mild iridium-catalyzed transformation of 1-thioalkynes into fully substituted triazoles with absolute regioselectivity (IrAAC), ${ }^{33-37}$ the uniqueness and high efficiency of which inspired us to envision motifs with two thioalkynyl substructures in serving as effective linear ABB-type building blocks (Scheme 1C). IrAAC reaction of these alkyne units with diverse organic azides are expected to generate various linear multifunctionalized triazole dimers. Re- 
tethering of them to the alkyne motif through successive azidation and IrAAC reaction will afford unsymmetrical triazole-based fragments, which could be further expanded into desired dendrimers through convergent synthetic approach.

In view of the above, we here report the assembly of nontraditional dendrimers by using this simple IrAAC-based protocol, the fidelity and efficiency of which were demonstrated by the construction of two dendrons from one linear alkyne motif. Further modifications of these dendrons on either the core or the surface were facilely achieved through different click reactions, resulting in the formation of newly functionalized dendrimers with up to $\sim 16.0 \mathrm{kDa}$ molecular weight. The identity and monodispersity of these unsymmetrically ramified macromolecules were well confirmed by ${ }^{1} \mathrm{H}$ NMR, MS and SEC analysis. We hope these nontraditional dendritic architectures together with the synthetic strategy introduced in this work will benefit the realm of dendrimer as well as corresponding functional applications.

\section{RESULTS AND DISCUSSION}

\section{Linear Alkyne Unit Preparation}

Various synthetic routes to 1-thioalkynes have been well established. ${ }^{38,39}$ Nevertheless, little attention was paid to the fabrication of linear oligothioalkynes. As outlined in Scheme 2, we designed the large-scale synthesis of linear alkyne building block (1) from the facile crosslinking of two 1-thioalkynes (S1 and S2, step vi in Scheme 2), both of which could be easily prepared from commercially available disulfides through simple synthetic strategies (S1: steps i-ii in Scheme 2; S2: steps iii-v in Scheme 2). Introduction of functional group for azidation was realized by subsequent functionalization with 4-toluenesulfonyl chloride (TsCl, step vii in Scheme 2). In consideration of diverse approaches to 1-thioalkyne motifs, rich variations in the functional group 
anchored to the sulfur atom in thioalkyne $\mathbf{S 1}$ as well as the linkage between its two thioalkynyl substructures are expectable.

Scheme 2. Preparation of Linear Alkyne Unit. ${ }^{a}$

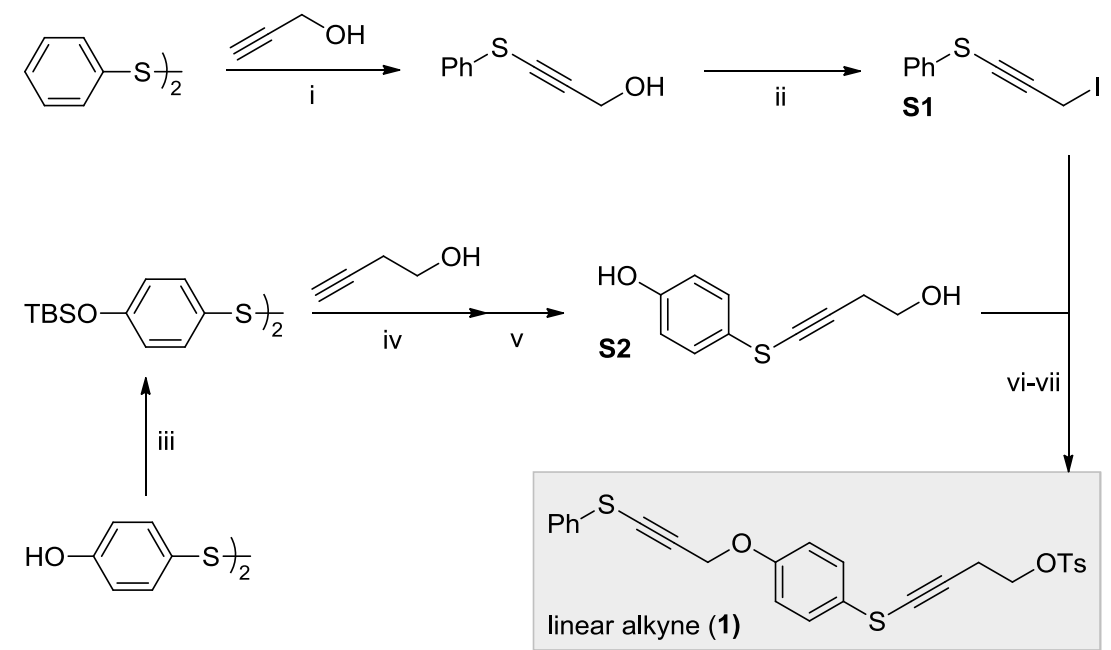

${ }^{a}$ Reaction conditions: (i) $n$-BuLi, EtI, THF, $\mathrm{N}_{2},-78{ }^{\circ} \mathrm{C}$ to r.t., 3 h, 80\%; (ii) $\mathrm{I}_{2}, \mathrm{PPh}_{3}$, imidazole, DCM, $0{ }^{\circ} \mathrm{C}$ to r.t., $1 \mathrm{~h}, 82 \%$; (iii) TBSCl, imidazole, DCM, $0{ }^{\circ} \mathrm{C}$ to r.t., 2 h, $99 \%$; (iv) $n$-BuLi, EtI, THF, $\mathrm{N}_{2},-78{ }^{\circ} \mathrm{C}$ to r.t., $3 \mathrm{~h}, 85 \%$; (v) TBAF, THF, $0{ }^{\circ} \mathrm{C}$ to r.t., $20 \mathrm{~min}, 95 \%$; (vi) $\mathrm{K}_{2} \mathrm{CO}_{3}$, acetone, $60{ }^{\circ} \mathrm{C}, 8$ h, 88\%; (vii) TsCl, Et 3 N, DMAP, DCM, $0{ }^{\circ} \mathrm{C}$ to r.t., 3 h, $93 \%$.

\section{Construction and Post-Modification of Unsymmetrical Dendrons}

We initiated our investigation on this IrAAC-based assembly of unsymmetrical branches by using benzyl azide as the cycloaddition partner of alkyne unit $\mathbf{1}$ (Scheme 3). As typical manipulation in dendrimer synthesis, an excess of the azide (2.20 equiv) was used to increase the yield of corresponding triazole motif. Conveniently monitored by thin-layer chromatography (TLC), the conversion of alkyne $\mathbf{1}$ was found to be completed in two hours under a simple and mild IrAAC condition (step i in Scheme 3). No requirement of additives and the absence of byproducts in this process enabled the facile separation of reaction mixtures by column chromatography to afford desired linear triazole block 2Bn-G1-OTs (2) in 85\% yield. ${ }^{1} \mathrm{H}$ NMR characterization (Figure S5 
in the Supporting Information) not only identified its exceedingly high purity, but also indicated the remained exclusive regioselectivity of the fully substituted triazole rings in this treatment, which is crucial for further precise constructions with excellent fidelity. Subsequent substitution of the tosylate group (OTs) with an azide unit was facilely achieved in the presence of an excess of sodium azide in dimethylformamide (DMF), generating $2 \mathrm{Bn}-\mathbf{G 1}^{-\mathrm{N}_{3}}$ (3) in $88 \%$ yield and $>99 \%$ purity (determined by ${ }^{1} \mathrm{H}$ NMR analysis, Figure S6 in the Supporting Information). In the next step, anchoring two of this azide motif to the original alkyne unit $\mathbf{1}$ through IrAAC reaction at room temperature provided the second-generation fragment 4Bn-G2-OTs (4) in 83\% isolated yield. Further propagations of dendron $\mathbf{4}$ to third- and fourth-generation unsymmetrical dendrons were easily accomplished by running one or two cycles of this mild and efficient two-step iterative strategy, enabling the fabrication of 16Bn-G4-OTs (8) as white solid in an overall yield of $27 \%$ from the initial step.

${ }^{1} \mathrm{H}$ NMR spectra of all dendrons involved in Scheme 3 (2-8) are provided in the Supporting Information (Figures S5-S11) to verify their precise chemical structure and high purity. The accomplishment of this unsymmetrical growth process is explicitly illustrated by the increased integrated intensities of proton resonances shown in these ${ }^{1} \mathrm{H}$ NMR spectra (Figures S13 and S14 in the Supporting Information). Size exclusion chromatography (SEC) analysis of OTsfunctionalized branches $(\mathbf{2}, 4,6$ and 8$)$ further identified their monodispersity and the successive expansion of their molecular size (Figure 1A). Characterization of dendron 8 by electrospray ionization mass spectrometry (ESI-MS) was also conducted to confirm its successful synthesis. As shown in Figure 1B, three predominant signals were observed in the mass spectrum (Figure 1B), all of which could be well assigned to its multiply-charged cations, including $[\mathrm{M} s+5 \mathrm{H}]^{5+}(\mathrm{m} / \mathrm{z}=$ 1549.2), $\left[\mathrm{M}_{8}+4 \mathrm{H}\right]^{4+}(m / z=1936.2)$, and $\left[\mathrm{M}_{8}+3 \mathrm{H}\right]^{3+}(m / z=2581.4)$. 
Scheme 3. Convergent Synthesis of Unsymmetrical Dendrons. ${ }^{a}$

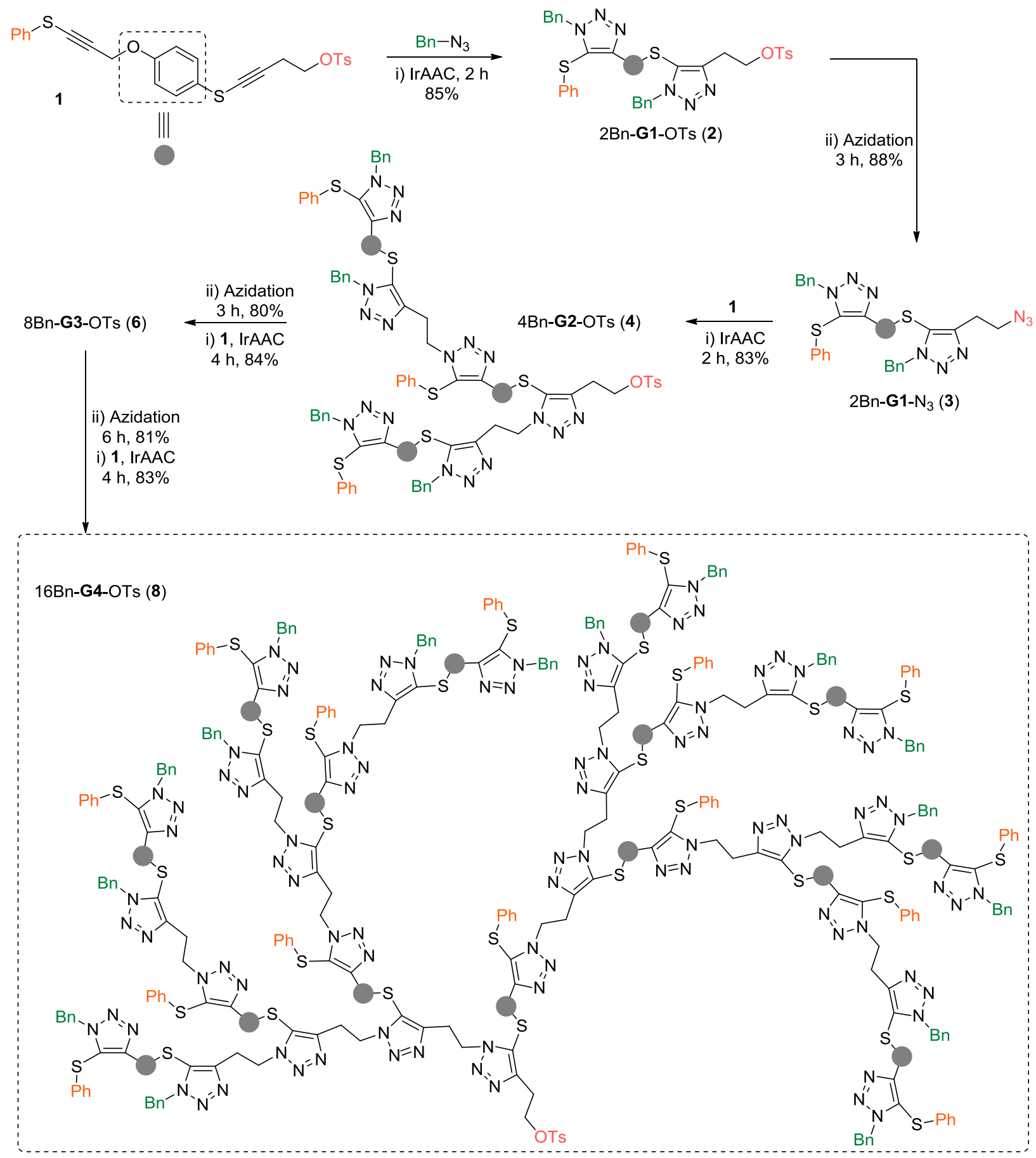

${ }^{a}$ Reaction conditions: (i) $[\operatorname{Ir}(\mathrm{COD}) \mathrm{Cl}]$, $\mathrm{DCE}, \mathrm{N}_{2}$, r.t.; (ii) $\mathrm{NaN}_{3}$, DMF, $80{ }^{\circ} \mathrm{C}$. 
A

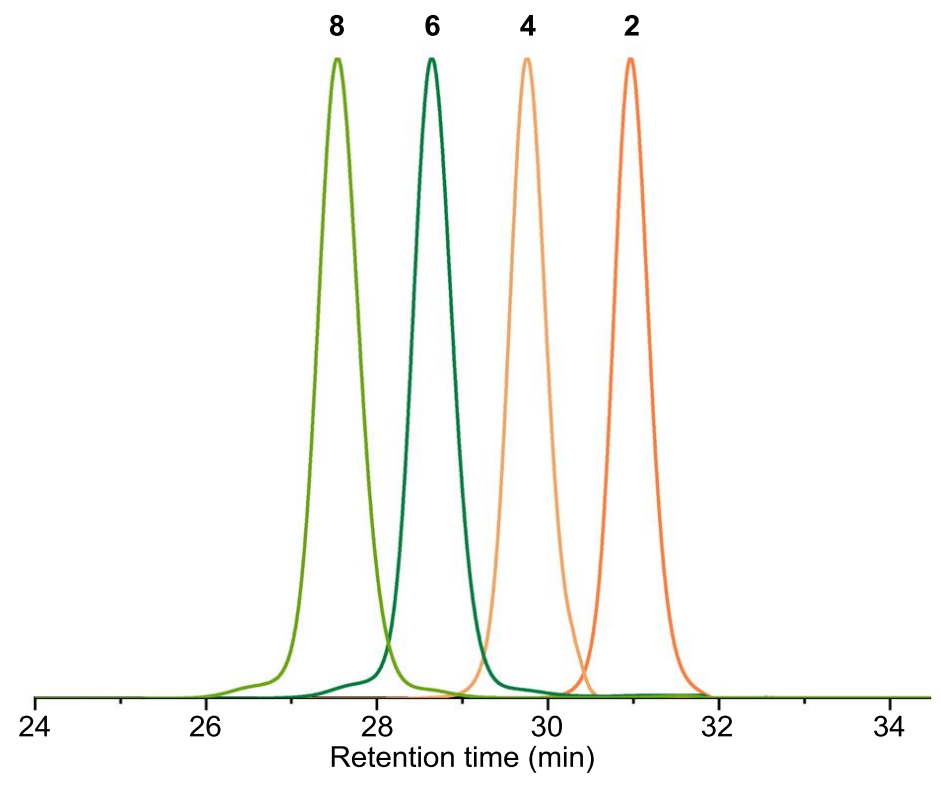

B

$$
\left[\mathrm{M}_{8}+4 \mathrm{H}\right]^{4+}
$$

1936.2

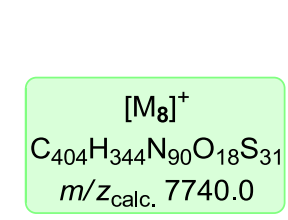

$\left[\mathrm{M}_{8}+3 \mathrm{H}\right]^{3+}$

2581.4
$\left[\mathrm{M}_{8}\right]^{+}$
$\mathrm{C}_{404} \mathrm{H}_{344} \mathrm{~N}_{90} \mathrm{O}_{18} \mathrm{~S}_{31}$
$\mathrm{m} / \mathrm{z}_{\text {calc. }} 7740.0$

$\left[\mathrm{M}_{8}+5 \mathrm{H}\right]^{5+}$

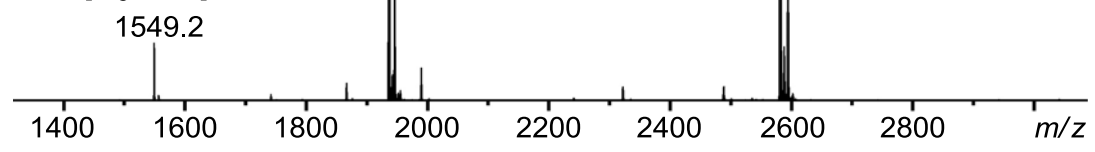

Figure 1. (A) SEC traces of 2, 4, 6, 8; (B) ESI-MS of 8. 
Scheme 4. Post-Modification of Dendron 8 (A) with ESI-MS analysis (B). ${ }^{a}$

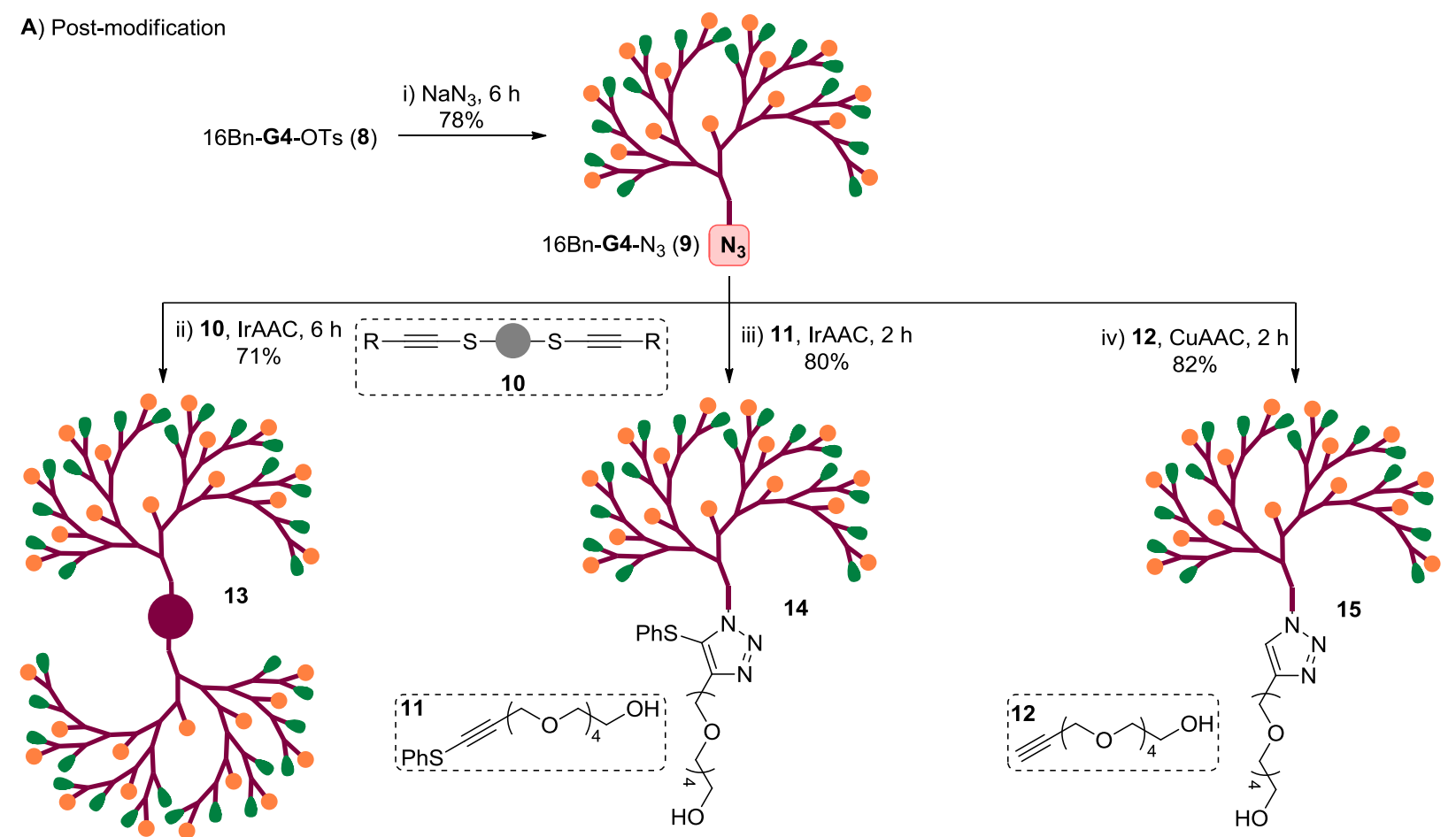

B) ESI-MS

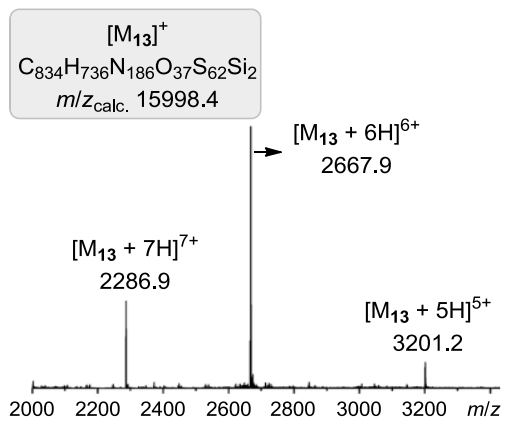

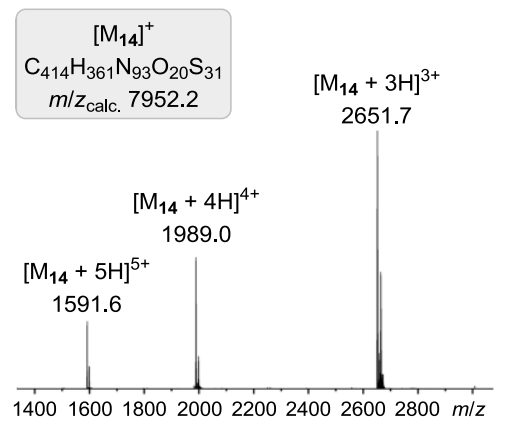

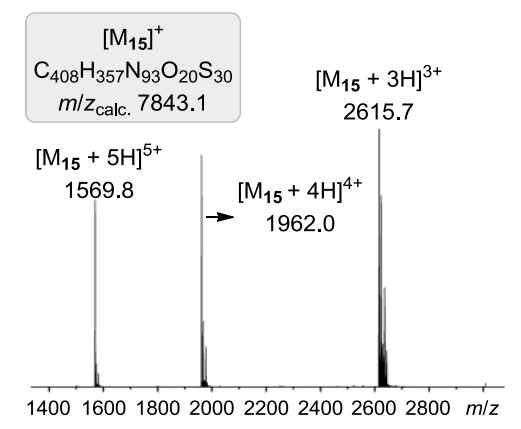

${ }^{a}$ Reaction conditions: (i) $\mathrm{NaN}_{3}, \mathrm{DMF}, 80^{\circ} \mathrm{C}, 6 \mathrm{~h}$; (ii) $[\operatorname{Ir}(\mathrm{COD}) \mathrm{Cl}] 2, \mathrm{DCE}, \mathrm{N}_{2}$, r.t., 6 h; (ii) $[\operatorname{Ir}(\mathrm{COD}) \mathrm{Cl}]_{2}, \mathrm{DCE}, \mathrm{N}_{2}$, r.t., 2 h; (iii) $\mathrm{CuBr}$, PMDETA, sodium ascorbate, DMF, $\mathrm{N}_{2}, 50{ }^{\circ} \mathrm{C}, 2$ h.

To learn the behavior of this new type of dendrons in comprising more complicated ramified architectures, post-modifications on the fourth-generation 16Bn-G4-OTs $(8)$ were next carried out (Scheme 4). The conversion of -OTs into $-\mathrm{N}_{3}$ could still proceed smoothly to provide $78 \%$ yield of highly pure $16 \mathrm{Bn}-\mathrm{G} 4-\mathrm{N}_{3}(9)$, which enabled further decorations with different alkynes by IrAAC or CuAAC (Scheme 4A). For instance, installation of this azido-functionalized dendron 9 
on one symmetrical skeleton bearing two thioalkynyl subunits (10) was conveniently achieved under benign IrAAC conditions for $6 \mathrm{~h}$ to afford corresponding dendrimer 13 in $71 \%$ yield. Alkynes with long hydrophilic chains (11 and $\mathbf{1 2})$ could be facilely introduced through these "click" reactions as well, resulting in amphiphilic dendrons (14 and 15) that have potential in assembling into noncovalent supramolecular dendrimers. ${ }^{40}$ All of the derived dendrimers (13-15) were well characterized by ESI-MS, the results of which are in excellent consistency with related theoretical values (Scheme 4B). ${ }^{1} \mathrm{H}$ NMR analysis further verified their high monodispersity and purity in an explicit manner (Figure S15-S17 in the Supporting Information).

Having disclosed the simplicity and efficiency of this mild synthetic approach, we next put our attention on the variations and decorations at the exterior layer of this unsymmetrical architecture. By virtue of the versatility of alkynyl group in organic transformations, development of alkyneterminated dendrimers is highly desirable. Intriguingly, silyl-protected internal alkynes were reported to exhibit high sluggishness in IrAAC ${ }^{33,34}$ On account of this, 1-silylalkynyl organic azide 16 was prepared for this construction (Scheme 5). As expected, the reaction of azide 16 with alkyne unit 1 under simple IrAAC conditions proceeded efficiently to give linear fragment 2TBS-G1-OTs (17) in $86 \%$ yield (Scheme 5A). By running three more cycles of this two-step protocol and one final TBS-deprotection operation, the alkyne-terminated fourth-generation dendron 16CC-G4-OH (24) was successfully obtained in an overall yield of $22 \%$. This expansion process was precisely tracked by SEC (Scheme 5B) and ${ }^{1}$ H NMR (Figures S26 and S27 in the Supporting Information) characterizations, through which the identity and high purity of these newly developed dendrons (17-23) were also well demonstrated. The ESI-MS spectrum of $\mathbf{2 4}$ presented in Scheme 5C showed two signals corresponding to multiply-charged cations, the values of which are highly consistent with the calculated values, thus confirming the successful obtainment of desired product. 
Scheme 5. Synthesis of Alkyne-Terminated Dendron (A) with SEC (B) and ESI-MS (C) Analysis. ${ }^{a}$

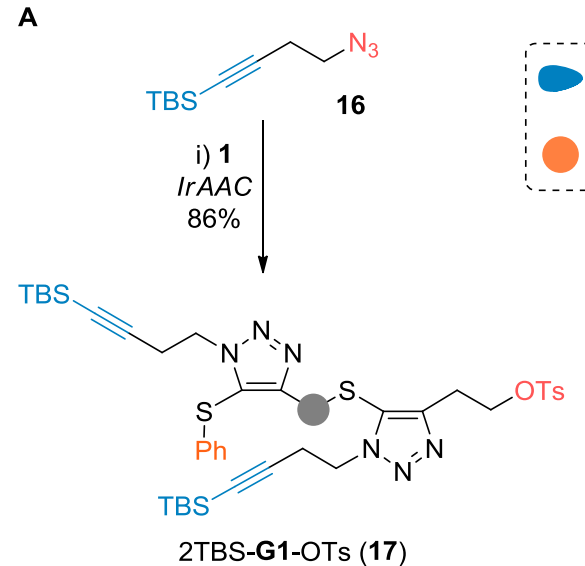

B) SEC traces

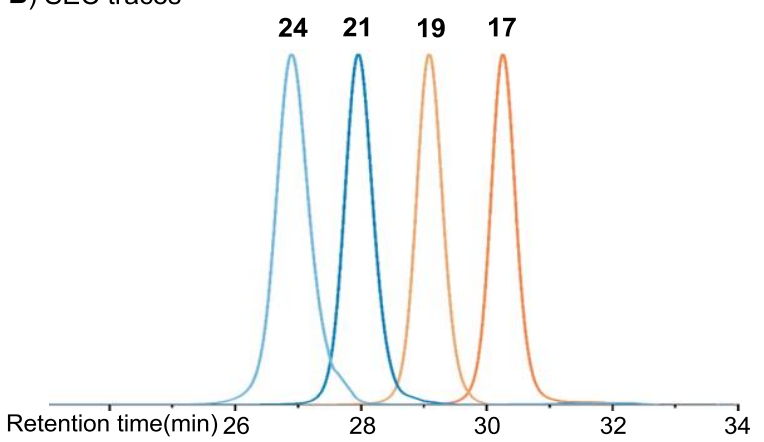

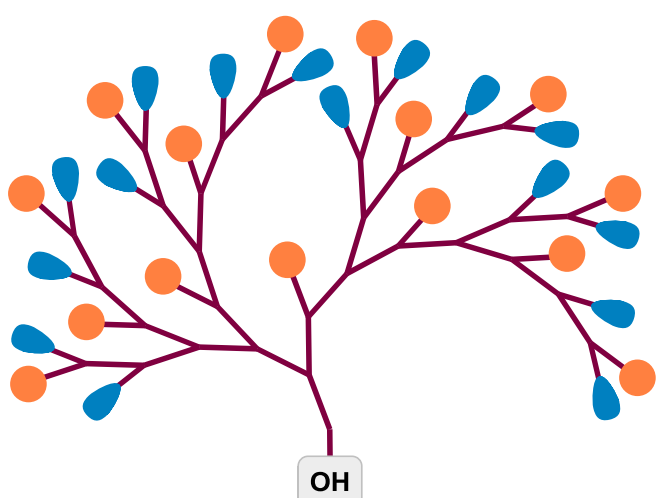

16CC-G4-OH (24)

$22 \%$ overall yield from 16

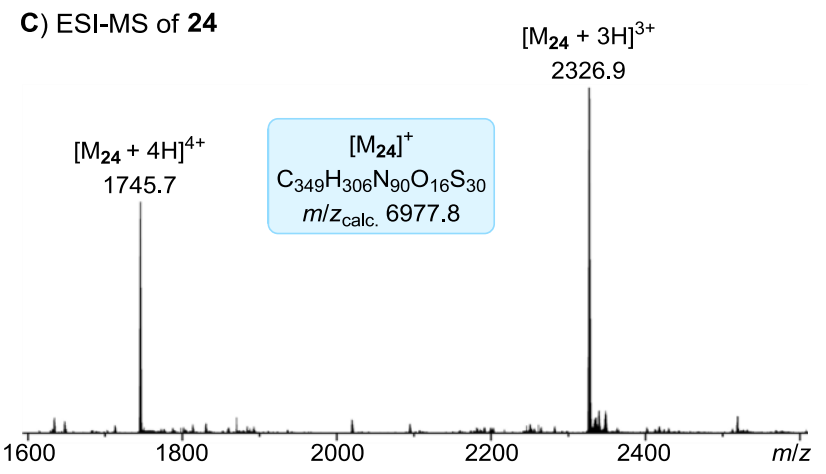

${ }^{a}$ Reaction conditions: (i) $[\operatorname{Ir}(\mathrm{COD}) \mathrm{Cl}] 2$, DCE, $\mathrm{N}_{2}$, r.t., 2-4 h; (ii) $\mathrm{NaN}_{3}, \mathrm{DMF}, 80{ }^{\circ} \mathrm{C}, 3-6$ h; (iii) TBAF, THF, $0{ }^{\circ} \mathrm{C}$ to r.t., $1 \mathrm{~h}$.

Subsequent decorations on these terminated alkynyl groups were conducted by using efficient coupling reactions, including $\mathrm{CuAAC}$ and thiol-yne reaction (Scheme 6). To probe the potential application of unsymmetrical framework in biomaterials, an adenine-involved organic azide (25) was selected for the CuAAC-based functionalization. The successful attachment of this azide to most of the alkynyl groups was confirmed by spectral analyses of the click product (26). As can be seen from the ${ }^{1} \mathrm{H}$ NMR spectrum of $\mathbf{2 6}$ (Figure S28 in the Supporting Information), the signal for the proton on the alkyne moiety $(2.0 \mathrm{ppm})$ nearly disappeared, while the integrated intensities of the signals for the protons of triazole $(7.4 \mathrm{ppm})$ and adenine $(8.3$ and $8.8 \mathrm{ppm})$ could achieve 
sixteen. More evidence for this success was provided by mass analysis. As shown in Scheme 6B, four groups of signals for multiply-charged cations were clearly observed in the ESI-MS spectrum of 26. While the major peaks in each group (a-c in Scheme 6B for instance) are well assigned to the desired product, the others ( $\mathbf{d}$ and $\mathbf{e}$ ) are related to dendrons incorporating fifteen azide units. Inspiringly, the modification through the thiol-yne process behaved in a more perfect fashion. In the presence of 2,2-dimethoxy-2-phenylaceophenone (DMPA), 32 units of the thiol were completely clicked onto $\mathbf{2 4}$ under ultraviolet irradiation to afford $80 \%$ isolated yield of $\mathbf{2 7}$, the high purity of which was identified by ${ }^{1} \mathrm{H}$ NMR (Figure S29 in the Supporting Information) and ESIMS (Scheme 6C) characterizations.

Scheme 6. Post-modification of Dendron 24 (A) with ESI-MS analysis (B-C). ${ }^{a}$

A) Post-modification

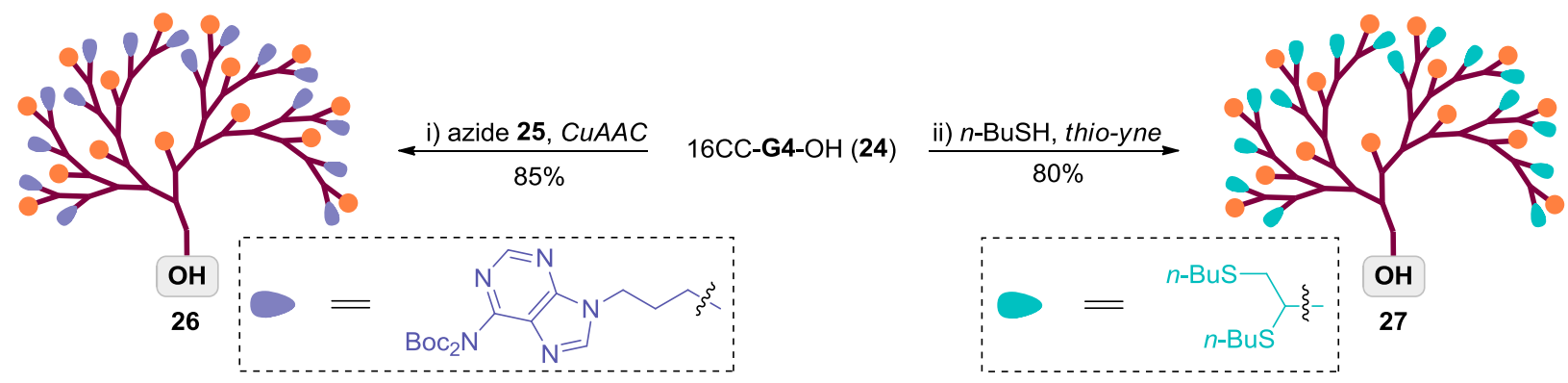

B) ESI-MS of $26^{b}$

$\left[\mathrm{M}_{26}+6 \mathrm{H}\right]^{6+}$

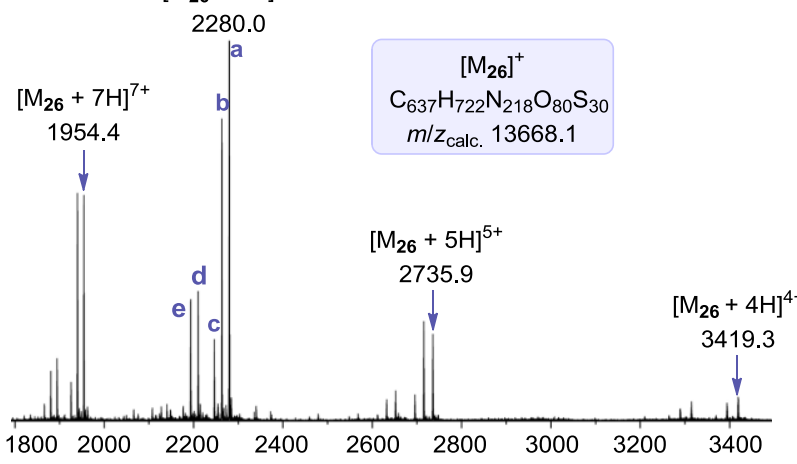

C) ESI-MS of $\mathbf{2 7}$

$$
\begin{gathered}
{\left[\mathrm{M}_{27}+4 \mathrm{H}\right]^{4+}} \\
2467.1
\end{gathered}
$$

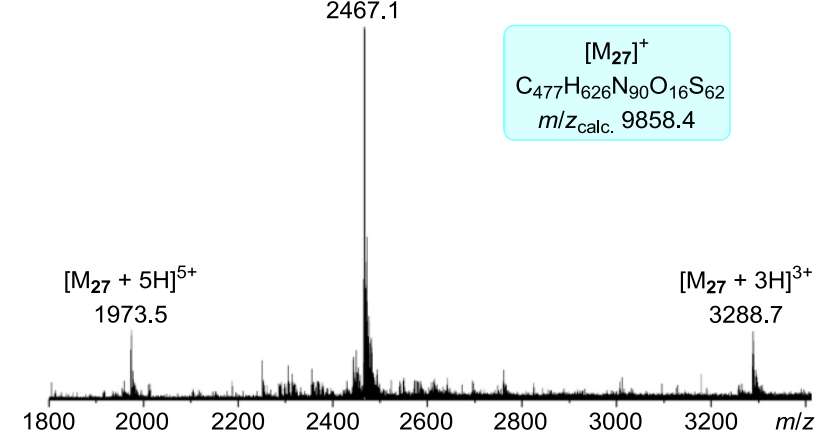

${ }^{a}$ Reaction conditions: (i) $\mathrm{CuBr}$, PMDETA, sodium ascorbate, DMF, $\mathrm{N}_{2}, 50{ }^{\circ} \mathrm{C}, 24 \mathrm{~h}$; (ii) DMPA, hv $365 \mathrm{~nm}$, r.t., 12 h. ${ }^{b} \mathbf{b}:\left[\mathrm{M}_{26}-\mathrm{Boc}+6 \mathrm{H}\right]^{6+}(\mathrm{m} / z=2263.3)$; $\mathbf{c}:\left[\mathrm{M}_{26}-2 \mathrm{Boc}+6 \mathrm{H}\right]^{6+}(m / z=2246.5)$; d: $\left[\mathrm{M}_{26}-\mathrm{RN}_{3}+6 \mathrm{H}\right]^{6+}(m / z=2210.2)$; $\mathbf{e}:\left[\mathrm{M}_{26}-\mathrm{RN}_{3}-\mathrm{Boc}+6 \mathrm{H}\right]^{6+}(m / z=2193.4)$. 


\section{CONCLUSIONS}

To sum up, in this contribution we demonstrated an unprecedented assembly of nontraditional dendrimers from linear ABB-type monomers. The convergent synthetic strategy established on robust IrAAC reaction showed high efficiency and fidelity in affording these unsymmetrically ramified architectures. Functionality owned by the initial linear thioalkyne monomer could be distributed throughout the dendritic structure due to the unsymmetrically growing manner, the diversity of which can be ensured by various approaches to 1-thioalkyne motifs. Meanwhile, the facile cooperation of the thioalkyne unit with different organic azides brings about rich variations on the functionality at the periphery. By virtue of the mild and convenient post-modifications on their core and out layer, assembly of these unsymmetrical dendrons into more complicated macromolecules exhibiting diverse three-dimensional forms is highly expected.

\section{ASSOCIATED CONTENT}

\section{Supporting Information.}

The Supporting Information is available free of charge at https://pubs.acs.org.

Synthetic procedure and additional spectroscopies data (PDF)

\section{AUTHOR INFORMATION}

\section{Corresponding Author}

Shengtao Ding - State Key Laboratory of Organic-Inorganic Composites, College of Chemical Engineering, Beijing University of Chemical Technology, Beijing 100029, China; orcid.org/ 00000003-1515-2931; Email: stding@mail.buct.edu.cn.

\section{Authors}


Lijiao Niu - State Key Laboratory of Organic-Inorganic Composites, College of Chemical Engineering, Beijing University of Chemical Technology, Beijing 100029, China.

Xueyan Zhang - State Key Laboratory of Organic-Inorganic Composites, College of Chemical Engineering, Beijing University of Chemical Technology, Beijing 100029, China; orcid.org/00000002-3526-0393.

\section{Notes}

The authors declare no competing financial interest.

\section{ACKNOWLEDGMENT}

This work was financially supported by the National Natural Science Foundation of China (No.

21871023), State Key Laboratory of Organic-Inorganic Composites (Beijing University of Chemical Technology).

\section{REFERENCES}

(1) Gade, L. H. Dendrimer catalysis; Springer-Verlag, Berlin Heidelberg: 2006.

(2) Boas, U.; Christensen, J. B.; Heegaard, P. M. H. Dendrimers in medicine and biotechnology: new molecular tools; The Royal Society of Chemistry, Cambridge: 2006.

(3) Vögtle, F.; Richardt, G.; Werner, N. Dendrimer chemistry: concepts, syntheses, properties, applications; Wiley-VCH, Weinheim: 2009.

(4) Caminade, A.-M.; Turrin, C.-O.; Laurent, R.; Ouali, A.; Delavaux-Nicot, B. Dendrimers: towards catalytic, material and biomedical uses; John Wiley \& Sons: 2011.

(5) Tomalia, D. A.; Christensen, J. B.; Boas, U. Dendrimers, dendrons, and dendritic polymers: discovery, applications, and the future; Cambridge University Press: 2012. 
(6) Klajnert, B.; Peng, L.; Cena, V. Dendrimers in biomedical applications; The Royal Society of Chemistry, Cambridge: 2013.

(7) Sharma, A. K.; Keservani, R. K. Dendrimers for drug delivery; Apple Academic Press: 2019.

(8) Chauhan, A.; Kulhari, H. Pharmaceutical applications of dendrimers; Elsevier Inc.: 2020.

(9) Campagna, S.; Ceroni, P.; Puntoriero, F. Designing dendrimers; John Wiley \& Sons: 2012.

(10) Malkoch, M.; Gallego, S. G. Dendrimer chemistry: synthetic approaches towards complex architectures; The Royal Society of Chemistry, Cambridge: 2020.

(11) Hecht, S. Functionalizing the Interior of Dendrimers: Synthetic Challenges and Applications. J. Polym. Sci. Part A: Polym. Chem. 2003, 41, 1047-1058.

(12) Smith, R. J.; Gorman, C.; Menegatti, S. Synthesis, Structure, and Function of Internally Functionalized Dendrimers. J. Polym. Sci. 2021, 59, 10-28.

(13) Piotti, M. E.; Rivera, F.; Bond, R.; Hawker, C. J.; Fréchet, J. M. J. Synthesis and Catalytic Activity of Unimolecular Dendritic Reverse Micelles with "Internal” Functional Groups. $J$. Am. Chem. Soc. 1999, 121, 9471-9472.

(14) Liang, C. O.; Fréchet, J. M. J. Incorporation of Functional Guest Molecules into an Internally Functionalizable Dendrimer through Olefin Metathesis. Macromolecules 2005, 38, $6276-6284$.

(15) Dichtel, W. R.; Hecht, S.; Fréchet, J. M. J. Functionally Layered Dendrimers: A New Building Block and Its Application to the Synthesis of Multichromophoric Light-Harvesting Systems. Org. Lett. 2005, 7, 4451-4454.

(16) Galliot, C.; Larré, C.; Caminade, A.-M.; Majoral, J.-P. Regioselective Stepwise Growth of Dendrimer Units in the Internal Voids of a Main Dendrimer. Science, 1997, 277, 1981-1984. 
(17) Larré, C.; Bressolles, D.; Turrin, C.; Donnadieu, B.; Caminade, A.-M.; Majoral, J.-P. Chemistry within Megamolecules: Regiospecific Functionalization after Construction of Phosphorus Dendrimers. J. Am. Chem. Soc. 1998, 120, 13070-13082.

(18) Séverac, M.; Leclaire, J.; Sutra, P.; Caminade, A.-M.; Majoral, J.-P. A New Way for the Internal Functionalization of Dendrimers. Tetrahedron Lett. 2004, 45, 3019-3022.

(19) Kang, T.; Amir, R. J.; Khan, A.; Ohshimizu, K.; Hunt, J. N.; Sivanandan, K.; Montañez, M. I.; Malkoch, M.; Ueda, M.; Hawker, C. J. Facile Access to Internally Functionalized Dendrimers through Efficient and Orthogonal Click Reactions. Chem. Commun. 2010, 46, $1556-1558$.

(20) Amir, R. J.; Albertazzi, L.; Willis, J.; Khan, A.; Kang, T.; Hawker, C. J. Multifunctional Trackable Dendritic Scaffolds and Delivery Agents. Angew. Chem. Int. Ed. 2011, 50, $3425-3429$.

(21) Albertazzi, L.; Mickler, F. M.; Pavan, G. M.; Salomone, F.; Bardi, G.; Panniello, M.; Amir, E.; Kang, T.; Killops, K. L.; Bräuchle, C.; Amir, R. J.; Hawker, C. J. Enhanced Bioactivity of Internally Functionalized Cationic Dendrimers with PEG Cores. Biomacromolecules 2012, 13, 4089-4097.

(22) Antoni, P.; Hed, Y.; Nordberg, A.; Nyström, D.; von Holst, H.; Hult, A.; Malkoch, M. Bifunctional Dendrimers: From Robust Synthesis and Accelerated One-Pot Postfunctionalization Strategy to Potential Applications. Angew. Chem. Int. Ed. 2009, 48, $2126-2130$.

(23) García-Gallego, S.; Andrén, O. C. J.; Malkoch, M. Accelerated Chemoselective Reactions to Sequence-Controlled Heterolayered Dendrimers. J. Am. Chem. Soc. 2020, 142, 1501-1509. 
(24) García-Gallego, S.; Stenström, P.; Mesa-Antunez, P.; Zhang, Y.; Malkoch, M. Synthesis of Heterofunctional Polyester Dendrimers with Internal and External Functionalities as Versatile Multipurpose Platforms. Biomacromolecules 2020, 21, 4273-4279.

(25) Wu, P.; Feldman, A. K.; Nugent, A. K.; Hawker, C. J.; Scheel, A.; Voit, B.; Pyun, J.; Frechet, J. M. J.; Sharpless, K. B.; Fokin, V. V. Efficiency and Fidelity in a Click-Chemistry Route to Triazole Dendrimers by the Copper(I)-Catalyzed Ligation of Azides and Alkynes. Angew. Chem., Int. Ed. 2004, 43, 3928-3932.

(26) Franc, G.; Kakkar, A. Dendrimer Design Using CuI-Catalyzed Alkyne-Azide “Click-Chemistry”. Chem. Commun. 2008, 5267-5276.

(27) Franc, G.; Kakkar, A. K. "Click”' Methodologies: Efficient, Simple and Greener Routes to Design Dendrimers. Chem. Soc. Rev. 2010, 39, 1536-1544.

(28) Astruc, D.; Liang, L.; Rapakousiou, A.; Ruiz, J. Click Dendrimers and Triazole-Related Aspects: Catalysts, Mechanism, Synthesis, and Functions. A Bridge between Dendritic Architectures and Nanomaterials. Acc. Chem. Res. 2012, 45, 630-640.

(29) El Brahmi, N.; El Kazzouli, S.; Mignani, S.; Bousmina, M.; Majoral, J. P. Copper in Dendrimer Synthesis and Applications of Copper-Dendrimer Systems in Catalysis: A Concise Overview. Tetrahedron, 2013, 69, 3103-3133.

(30) Arseneault, M.; Wafer, C.; Morin, J.-F. Recent Advances in Click Chemistry Applied to Dendrimer Synthesis. Molecules 2015, 20, 9263-9294.

(31) Geng, Z.; Shin, J. J.; Xi, Y.; Hawker, C. J. Click Chemistry Strategies for the Accelerated Synthesis of Functional Macromolecules. J. Polym. Sci. 2021, 59, 963-1042.

(32) Ma, J.; Ding, S. Transition Metal-Catalyzed Cycloaddition of Azides with Internal Alkynes. Asian J. Org. Chem. 2020, 9, 1872-1888. 
(33) Ding, S.; Jia, G.; Sun, J. Iridium-Catalyzed Intermolecular Azide-Alkyne Cycloaddition of Internal Thioalkynes under Mild Conditions. Angew. Chem., Int. Ed. 2014, 53, 1877-1880.

(34) Ju, C.; Meng, C.; Ma, J.; Zhang, X.; Ding, S. Construction of Sequence-Defined Polytriazoles by IrAAC and CuAAC Reactions. Chem. Commun. 2020, 56, 3955-3958.

(35) Zhang, X.; Gou, F.; Wang, X.; Wang, Y.; Ding, S. Easily Functionalized and Readable Sequence-Defined Polytriazoles. ACS Macro Lett. 2021, 10, 551-557.

(36) Wang, X.; Zhang, X.; Wang, Y.; Ding, S. IrAAC-Based Construction of Dual SequenceDefined Polytriazoles. Polym. Chem. 2021, 12, 3825-3831.

(37) Wang, X.; Zhang, X.; Sun, Y.; Ding, S. Stereocontrolled Sequence-Defined Oligotriazoles through Metal-Free Elongation Strategies. Macromolecules 2021, 54, 9437-9444.

(38) Gray, V. J.; Wilden, J. D. The Chemistry of Ynol and Thioynol Ethers. Org. Biomol. Chem. 2016, 14, 9695-9711.

(39) Santandrea, J.; Godin, E.; Collins, S. K. A Synthetic Guide to Alkynyl Sulfides. Org. Biomol. Chem. 2020, 18, 4885-4893.

(40) Lyu, Z.; Ding, L.; Tintaru, A.; Peng, L. Self-Assembling Supramolecular Dendrimers for Biomedical Applications: Lessons Learned from Poly(amidoamine) Dendrimers. Acc. Chem. Res. 2020, 53, 2936-2949. 